\title{
The Empirical Research of the College Students' Media Literacy in Mass Media Situation
}

\author{
Bin $\mathrm{Li}^{1, \mathrm{a}^{*}}$, Su Huo ${ }^{2, \mathrm{~b}}$ and Nan Zhao ${ }^{3, \mathrm{c}}$ \\ 1 Jilin Agricultural University, No.2888.Xincheng Street, Changchun, China,130118* \\ ${ }^{2}$ Jilin University, No. 2699.Qianjin Street, Changchun, China, 130013 \\ ${ }^{3}$ Northeast Normal University, No.2555.Jingyue Street, Changchun, China,130024 \\ a105289129@qq.com, b280339877@qq.com, ${ }^{c} 105289129 @ q q . c o m$
}

Keywords: Entertainment; College Students; Media Literacy

\begin{abstract}
The objective of paper is to investigate the current situation of University college students' network media literacy and exploring methods. We use the empirical research method to study based on the data of Jilin Agricultural university students media behavior and media literacy. The paper have some research results and got the conclusion: approaches of network media literacy education for college students to accept under the entertainment-communicating background, by the way of questionnaire, so that these can resolve the problem of who lack network media literacy. To hope that colleges and universities can put college students' network media literacy education on the agenda, and to hope that the empirical study can provide reference function for the approaching universal process of network media literacy.
\end{abstract}

\section{Introduction}

Many scholars abroad consider that media literacy is a reaction capacity for distinguishing, choosing, understanding, querying, evaluating, creating and thinking critically media information. Although scholars from all over the world have different views and emphases for the research of media literacy, it also reflects that some foreign countries pay high attention to media literacy. And western countries are improving media literacy education gradually, it's more better than the development in China.

Domestic scholars identify the concept of the English scholar David Parkin translated by Xiaowei Song: It's the healthy media criticism ability that makes college students take full advantage of media resources to improve themselves and to take part in social development. There are also other domestic scholars have their own understanding. Many scholars voice their own opinions, But their opinions mostly base on superficial understanding, and theoretical understanding is not applying to actual operation and having essential recommendation. Furthermore, except some domestic scholars' opinions, each university has the lower understanding of the media literacy education and media literacy education is at the initial stage.

As the rapid expansion of mass media technology, we gradually come into an era called information globalization. The relevant researches aimed at media literacy education gradually turn into an important part in communication research field. For the problem that present entertainment communication produces negative effects and it makes the lack of media literacy for college students' network media literacy, the college students' media literacy education will be the focus of each university and even the whole society in the future, it will also be an important index for cultivating high-quality and excellent college students.

The definition of entertainment communication in the book Amusing Ourselves to Death interprets that, our policy, religion, news, sports, education and business become appendage of entertainment without protest, with no complaint and even without any sound, the result is that we become the species of amusing ourselves to death. 


\section{Empirical Research and Survey Design}

College students' network media literacy becomes the focus in all quarters of the society increasingly because entertainment information spreads recklessly and network media develops quickly, therefore, this text chooses Jilin Agricultural University students as respondents and adopts the way of sample survey in questionnaire to the detailed investigation and statistics of college students' network media literacy.

Questionnaire Design. By the way of sample survey, students in each grade have been investigated, and the questionnaire involve questions as follow. This survey have made simple distinction and statistics from the aspects of sex, grade and specialty respectively. By inquiring about the familiarity of the term "media literacy", the author understands the present situation of media literacy in college students' life. By inquiring about what media the college students use to get information, how long they use network media each day, what motivation they are and what content they use media, the author understands the degree of university students' dependence on the network media. By understanding the attitude of college students to the network of information and the way of selection of various types of information can also show that whether the media literacy education in college students as a key content in the following study and life, etc.

Investigation Hypothesis and Status. The respondents in this text are college students who are at school at every grade of agricultural university. The survey was conducted by means of a unified questionnaire and random sampling. The investigators have surveyed at the campus, classroom, dormitory and other places. To select the university students as a model for investigation, because the university is a comprehensive university with both liberal arts majors and science related professional. Therefore, it can respond status quo of college students' network media literacy accurately. A total of 100 questionnaires were collected, and 81 questionnaires are valid, with an effective rate of $94.2 \%$.

Through the questionnaire survey and data analysis, it shows that the scope of the respondents is still wide, and the questionnaire involve various grades of various professions; while most of the respondents in the questionnaire for the question whether they understand the media literacy are generally answered ,but they did not understand what the meaning of that, and there are also a small number of people did not hear the word, only a small part students majored in mass communication understand the word; meanwhile, in the questionnaire, most of the students get information from the network, mobile phones and other mass media, and they are very dependent on the network, furthermore, the time which they use the Internet every day is too long.

And many students get the network information with no clear plans and goals, most of them are free to browse, and the purposes are not clear. However, from the questionnaire we can find that the media literacy education is recognized by college students and they are looking forward to the media literacy education .

\section{Survey Results and Analysis}

Cognitive Status of Media Literacy. In the questionnaire survey, for the situation that the agricultural university students learn about the media literacy, the data shows that $60 \%$ of the students said they just heard, but they do not understand specific content; and $21 \%$ of the students are completely unaware of this word; $15 \%$ of the students are relatively learn about it; and only $4 \%$ of the students understand it thoroughly. And from the data is not difficult to see, it is only a small part of people that understand the concept of media literacy, most of the students treat this vocabulary as a stranger, or even never heard, it also shows that Jilin Agricultural University students are at the initial stage in the cognitive media literacy.

Assess Ways of Information Acquisition. In the survey, the data shows that there are several channels the students choose to obtain information, $8.4 \%$ of the students choose to get information from the newspaper and other paper version, $12.9 \%$ of the students get their own information by listening to the radio, $17 \%$ Of the students know the daily we want to know the information through the TV, and $61.7 \%$ choose network, $88.4 \%$ of the students obtain information through the mobile 
APP or social media . From these data, it is not difficult to learn that the ways of the daily access to information for students are mostly from the network, and they are dependent on this carrier, this is also the reason why current social network has become thriving channels of communication and access to information to understand the world.

Status of Network Media Contact Condition. From the questionnaire survey, we know that students have more time to contact the Internet every day. $19.2 \%$ and $23.1 \%$ of the students use the network in 1 hours and 2 hours every day, only $14.3 \%$ of the students said their daily online time in about half an hour, and most of the students said they use the network more than 3 hours. It also shows that the network has become an indispensable part of the daily life for the students, they are so dependent on the network, this phenomenon would have a great impact on their daily learning, normal life, even they are too obsessed with the network to study .

Motion of Network Media Exposure. Students use the network for leisure and entertainment, information needs, access to knowledge, social communication and time-spending in general. And $43.6 \%$ of the students said that they contact the media in order to information, in other words, most of the students obtain information through the network, which makes the students need their own information discrimination when they face complex and massive information. At the same time there are some students for leisure and entertainment to use the media, but only entertainment often makes students the spirit of the emptiness. And some students use the media is to spend time, which shows some of the students have bad values, the students' media literacy can not stay with the current situation, but their media literacy education.

Attitude of Treating Entertainment Communication. It is easy to see that most students show the indifferent attitude on the current phenomenon of media entertainment, their ambiguous and aimless attitude also shows that the students pay no attention on the media entertainment phenomenon, let alone their own views. I have concluded that the students of Jilin Agricultural University need to improve their media literacy and need to continue to learn and improve.

From the results of the survey, we can know that most of Jilin Agricultural University students are unclear for media literacy. They are still in a hazy state of confusion and media literacy awareness is weak. To strengthen media literacy education should become the important point of college students later their learning. Meanwhile, too long time the students use the network and their dependence can also show that students use network in an improper way. Excessive network-using makes students lose abilities of reading and writing and thinking. Using the network blindly makes them simplify thinking and it is easy to waste their study time. From the ambiguous plans and ambiguous purposes of college students' information demand, we can also see that the students' network rules are comparatively neglected. From the questionnaire, we can also see that students are not offensive about the media literacy education, instead their attitudes of supporting the media literacy education should be put on the agenda.

Nowadays, all kinds of information are coming, information received every day by the thousands makes the contemporary college students' vision broaden, makes them knowledgeable, and makes them no longer confine to only knowledge in books, but the latest news immediately informed from all over the world. Meanwhile, entertainment information spread extensively which makes students' study life more rich and colorful; students can get information more conveniently and quickly. But at the same time, many college students blindly rely on the network media so that they lose the ability of thinking alone and they do things simply. Fuqin Liu said that, in the article named media literacy education of College Students under the background of entertainment mass media, if the mass media carries a large entertainment functions, which confused the forms of communication and communication function. The impact of entertainment communication, all kinds of information with no strict screening and norms and college students with low media awareness, make college students form a lot of bad habits in the network; and a series of adverse effects also make the college students' world outlook, life outlook and values be affected. And these negative effects will affect the students' future learning and life.

Therefore, through the analysis of the questionnaire, we can see that today's society, colleges and universities and college students have the following problems. The quick development of market 
economy makes the social environment of the network supervision not keep up with the speed of information dissemination so that information spread without restraint ; Influential people in the cultural field has been driven by the interests regardless of the network environment, they damage the environment voluntarily, so the network is no longer clear; the colleges and universities are not treating the media literacy course as a compulsory course for students, and ignoring media literacy training for the students.

\section{Results and Conclusion}

The college students should enhance their own culture, Yishan Sun said in the book called The social meaning of executing the college students' media literacy education: Make college students take part in the process of producing information, in order that they can get personal motion. Therefore, the college students should enhance their own culture, resist harmful information consciously, enhance self controlling force, put an end to browse violent or pornographic website and study Internet code of conduct voluntarily. From individual effort, there is no personal ill web records, there is no so-called malignant communication.

Jiang Jian and Xiaoxia Kuang have pointed out in the book Campus media: the valid ways of enhancing the college students' media literacy education, colleges and universities provide new ways for college students' media literacy education in the way of the young easily accept, and lead them to distinguish and analyze media phenomenon in scientific opinion. So that, every university should set up campus media, such as campus newspaper, campus website and broadcast as so on, meanwhile, universities should propagandize and explain media literacy on campus. Universities should treat media literacy as a course, make related plans and arrangement.

Xiaohuang Chen have pointed out in the text called Explore and Analysis the problem of college students media literacy absence: the media as gatekeepers should highlight the themes of the times consciously, keep away from the exportation of harmful information and cultural production, persist in inspiring college students by excellent works and lead them in lofty character in aspects of information-making and information-production. Therefore, relevant media and departments of cultural communication should strengthen supervision for information-spreading, harmful information should been eradicated from the source completely and directly, some statements and behavior harmful to communication should been banned in the Internet and should not propagate without restraint, the related departments can also set up healthy website and issue some positive information on website media regularly in order to make healthy information communication platform.

This paper conclusion is different from others before in the method using and research perspectives. The author have not only learned about the current state of Jilin Agricultural University students' media literacy, by the empirical approach, but prompted a series of related suggestions after the author have analyzed the following disadvantage under the entertainment communication, in order that they can make all aspects of society involved college students have a new sight of media literacy. College students' media literacy education which the colleges should put it on the agenda and looking forward to the referential significance which this empirical study produced for the later popularization process of network media literacy.

\section{Acknowledgement}

This research was financially supported by Jilin province social science fund project: The new media of Jilin rural cultural communication mechanism in the perspective of empowerment (2016B270) and Jilin province education science planning office program: Research on education training mode of communication practical cultivation of talents based on rural culture service (GH170263) 


\section{References}

[1] Liuming Zhou. Media Literacy of University Students Research Status. (Ph.D., Huazhong Agricultural University, China 2015), p4-8.

[2] David, P. John. The British Media Literacy Education: Beyond Protectionism. Journal of Journalism and Communication research, 33(2015) 24-26.

[3] Neil Postman. Amusing Ourselves to Death. Guangxi Normal University Press, Guilin,2016.

[4] Fuqin Liu. Under the Background of the Mass Media Entertainment of College Students' Media Literacy Education. China Medical Education Technology, 50 (2017) p41-42. 